\title{
Mixed Martial Arts: History, Physiology and Training Aspects
}

\author{
Tácito P. Souza-Junior ${ }^{1, *}$, Bernardo N. Ide ${ }^{2}$, Jeffer E. Sasaki ${ }^{3}$, Rafael F. Lima ${ }^{1}$, Cesar C. C. Abad ${ }^{4}$,
} Richard D. Leite ${ }^{5}$, Marcelo P. Barros ${ }^{1,6}$ and Allan C. Utter ${ }^{7}$

\author{
${ }^{I}$ Department of Physical Education, Federal University of Parana, Curitiba, P.R. Brazil \\ ${ }^{2}$ Department of Biochemistry, State University of Campinas, Campinas, SP, Brazil \\ ${ }^{3}$ Department of Sport Sciences, Federal University of Triangulo Mineiro, Uberaba, MG, Brazil \\ ${ }^{4}$ InCor, University of Sao Paulo, Sao Paulo, SP, Brazil \\ ${ }^{5}$ Department of Physical Education, Federal University of Maranhão, São Luís, MA, Brazil \\ ${ }^{6}$ Institute of Physical Activity and Sport Sciences, University of Cruzeiro do Sul, São Paulo, SP, Brazil \\ ${ }^{7}$ Department of Health, Leisure, and Exercise Science, Appalachian State University, Boone, NC, USA
}

\begin{abstract}
Objective: The purpose of this study was to review current knowledge on exercise physiology and sports training that can be applied to develop training programs for Mixed Martial Arts. Methods: A non-systematic literature review was conducted to search for articles related to history, physiology and training of Mixed Martial Arts and other Martial Arts such as Judo, Wrestling, Jiu-Jitsu, and Karate. A review on aerobic, anaerobic, strength and power training was also conducted and directly related to Mixed Martial Arts training. Results: There is scarce scientific information about training methods and physiological responses to specific efforts in Mixed Martial Arts. Many studies were reviewed and meaningful information on physiology and training were summarized for application in Mixed Martial Arts. Conclusion: The present study provides a review on important physiology and training aspects for successful preparation of Mixed Martial Arts athletes.
\end{abstract}

Keywords: Combat sports, Mixed Martial Arts training, Mixed Martial Arts Physiology.

\section{INTRODUCTION}

Martial arts have been practiced since $5000 \mathrm{BC}$ and have lately been defined as defensive and offensive combat systems with or without weapons [1]. The Mixed Martial Arts (MMA) is a combat sport originated from ancient fighting techniques dating from $649 \mathrm{BC}$ [2]. In the modern era, MMA resurged from Vale-tudo events in the early 90's promoted by Masters Carlos and Helio Gracie. Currently, the event called Ultimate Fighting Championship (UFC) has been attracting thousands of fans worldwide, especially after the implementation of the current rules in 2009. The growth of MMA is unquestionably a great phenomenon recently observed in combat sports [3]. Despite its current popularity, scientific literature still lacks information about the characterization of efforts, resources, training methods, as well as physiological responses to specific efforts during the

\footnotetext{
*Address correspondence to this author at the Universidade Federal do Paraná - UFPR, Centro de Pesquisa em Exercício e Esporte - CEPEE, Grupo de Pesquisa em Metabolismo, Nutrição e Treinamento de Força GPMENUTF, Rua Coração de Maria, 92 - Curitiba/PR, BR 116, km 95 Campus Jardim Botânico, CEP: 80210-132, Brazil; Tel: (41) 3360-4325;

E-mails: tacitojr@ufpr.br, tacitojr@me.com
}

MMA fight. Therefore, the purpose of this study was to review current knowledge on exercise physiology and sports training that can be applied to develop training programs for Mixed Martial Arts.

\section{CONTEMPORARY HISTORY}

Mixed Martial Arts is an exciting and complex combat sport that combines techniques of Brazilian Jiu-Jitsu, Boxing, Muay Thay, Kickboxing, Wrestling and others. Perhaps, the most attractive aspect of MMA is the search for the perfect combination of grappling and striking techniques, which obviously requires many skills and fight strategies from MMA athletes when competing against different opponents. Most professionals and fight enthusiasts consider that MMA was officially launched in November $12^{\text {th }}, 1993$ (Denver, USA) with the "Ultimate Fighting Championship" (UFC) event created by Rorion Gracie, the eldest son of Master Helio Gracie [4]. In the beginning, the UFC was conducted as simple unregulated challenges between fighters, who intended to demonstrate the supremacy of their original techniques. In the first edition, weight divisions and time limit were not established and Royce Gracie (Rorion Gracie's brother), weighing $83.01 \mathrm{~kg}$, was the winner after surpassing 
Table 1. Body mass categories in MMA.

\begin{tabular}{|c|c|}
\hline Category & Body Mass (kg) \\
\hline \hline Flyweight & $<56$ \\
\hline Bantamweight & $56-61$ \\
\hline Featherweight & $62-66$ \\
\hline Lightweight & $67-70$ \\
\hline Welterweight & $71-77$ \\
\hline Middleweight & $78-84$ \\
\hline Light Heavyweight & $85-93$ \\
\hline Heavyweight & $94-120$ \\
\hline Super Heavyweight & $>120$ \\
\hline
\end{tabular}

even heavy weight fighters ( $>94 \mathrm{~kg}$ ). Currently, MMA fights consist of three (no title defense) or five rounds (title defense) of 5 minutes with 1-minute rest between rounds. Competitors are currently divided into categories of body mass (Table 1) and levels of experience (competition ranking) [5]. In addition, competitors use protective equipment consisting of a mouth guard, genital protection cap, and gloves of 4-6 oz. The rounds are interrupted by the referee when one competitor is finalized by submission, technical knockout, knockout, disqualification for breaking competition rules or when the round time is over $[5,6]$.

\section{PHYSICAL TRAINING FOR MMA}

The physical efforts during a MMA fight are predominantly characterized as intermittent, which means that during competition athletes usually perform high intensity actions interspersed with short rest periods and/or lower intensity actions. Studies measuring post-fight plasma lactate concentrations and rate of perceived exertion have shown values ranging from 10.2 to $20.7 \mathrm{mmol} . \mathrm{L}^{-1}$, and 13 to 19 , respectively [7]. Such observations reveal high intensity efforts with meaningful participation of the lactic anaerobic metabolism during a fight [7]. The wide range in lactate values is probably due to the variability of intensity in different fights. While many reports about training sessions of intermittent modalities are currently available in the literature, little is known about more specific and efficient means and methods for improving physical performance in MMA. In the next few sections, we discuss some important physical training concepts and knowledge that can be applied to improve MMA performance.

\section{ENDURANCE TRAINING}

Endurance capacity is related to increases in activity of key enzymes from the electron transport chain as well as an increase in mitochondrial density [8]. These metabolic changes, together with the increase of capillary density, result in trained muscle with higher capacity for using fatty acids as energy substrate, thus, reducing the reliance on the anaerobic lactic metabolism [8].

One of the best methods to increase endurance capacity in MMA athletes is the execution of regular specific training sessions of Muay Thai, Boxing, Wrestling, or Brazilian Jiujitsu [4]. This type of training helps to improve endurance capacity and allow athletes to learn and consolidate new technical gestures in a real fight situation. A well-designed training program also involves organization and quantification of intensity and volume of exercises [8]. For modalities with cyclic movement such as running, the intensity may be prescribed more precisely using incremental stress tests to identify the running speed where the ventilator threshold and/or respiratory compensation point occur [9]. In MMA, however, no objective parameter is available for monitoring training intensity during sparring. Therefore, professionals working with physical conditioning of MMA athletes need to identify subjective parameters that can be used to dictate increments in the training process. For example, MMA fighters usually demonstrate changes in movement pattern when they become tired (e.g., decrements in technique). Coaches can gauge the intensity of sparring sessions based on these changes.

\section{INTERVAL TRAINING}

Interval training involves alternating stimulation and rest or a reduction in stimulation intensity. From a practical standpoint, an advantage of interval training compared to continuous training is the possibility of performing higher volumes of high intensity activities per training session [10]. The intermittent nature of the method induces alternations in intramuscular concentrations of phosphocreatine and glycogen, as well as in plasma lactate and $\mathrm{H}^{+}$.

One example of interval training for MMA is the alternation of rounds lasting about 2 minutes with recovery periods ranging from 1 to 4 minutes [4]. An important consideration in relation to recovery is that a slower removal of lactate and $\mathrm{H}^{+}$from the muscle to the blood occurs when passive recovery is employed between stimulations, causing a slower restoration of intramuscular $\mathrm{pH}$ [11]. Conversely, this type of recovery provides a higher index of phosphocreatine resynthesis, which can be an advantage for the maintenance of performance in subsequent stimulations. The active recovery promote a faster removal of the lactate released into the blood to tissues such as liver, heart and type I fibers [11, 12]. A further example of an interval exercise for MMA consists of punching sandbags (15 seconds at moderate speed and 15 seconds at high speed) followed by sprawls (defensive techniques to avoid takedowns) [4]. Similarly, other specific fight techniques and combat simulations can be adapted as interval exercises to enhance MMA athletes' performance [4]. This involves alternations of striking techniques (e.g., punching, kicking, elbowing) with defense and grappling movements. Combat simulation needs to be emphasized in MMA as it presents the closest resemblance to what occurs in a fight in terms of energy metabolism. 

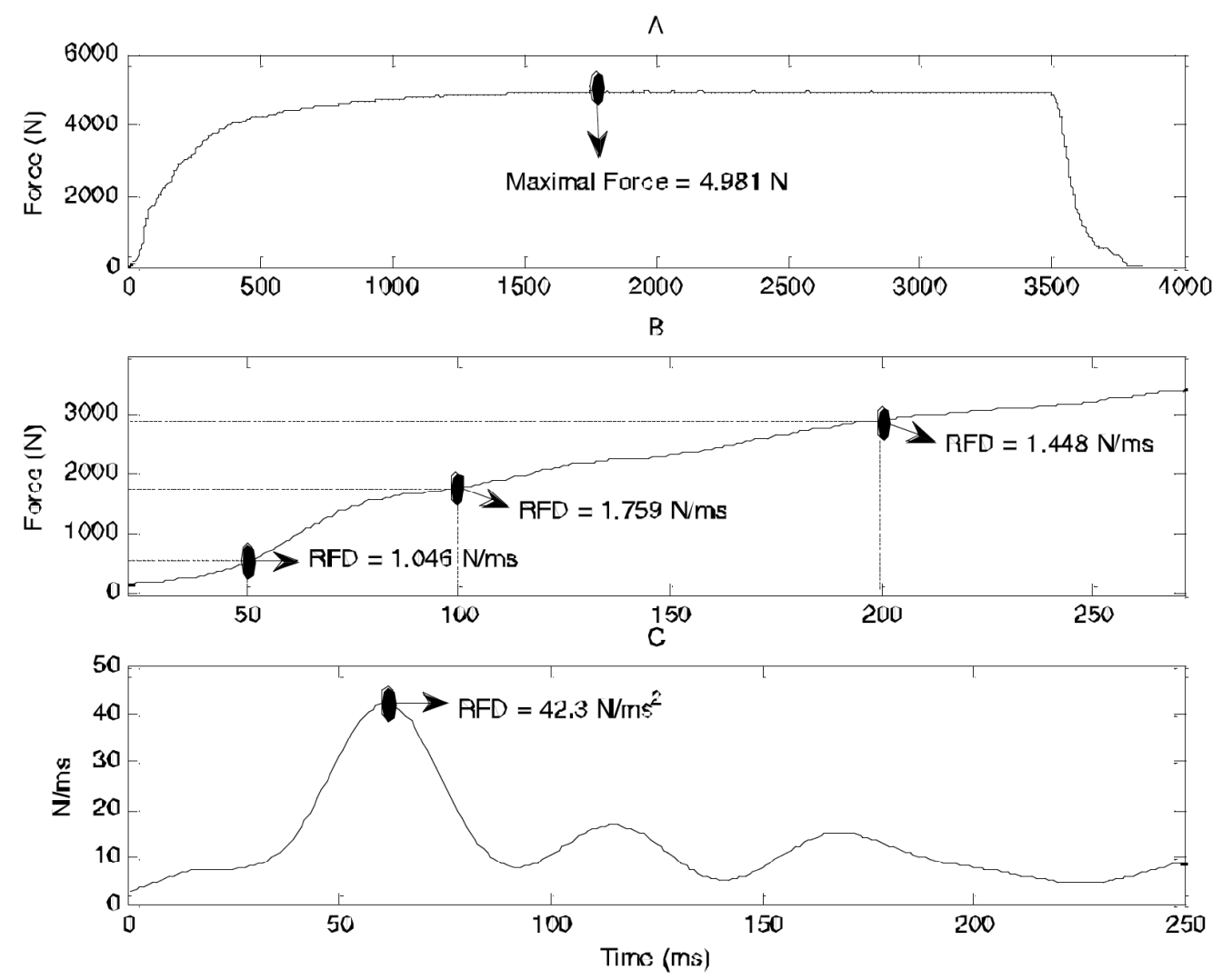

Fig. (1). A) Force/Time curve obtained in a maximum voluntary isometric contraction in Leg Press $45^{\circ}$ exercise; B) Rate of force development (RFD) expressed by the force production in fixed intervals of 0-50, 0-100 and 0 - $200 \mathrm{~ms}$ for the start of the contraction; C) RFD expressed by the peak of the first derivative of the force/time curve.

\section{STRENGTH AND POWER}

Muscle strength and power are required in different forms and magnitudes during sport activities. Among them, the literature highlights activities such as sprints, kicks, throws, punches, jumps and direction changes $[13,14]$. In MMA athletes, a special attention should be paid to isometric strength. Since no displacements are observed in isometric actions, the work performed is theoretically zero, with no power being produced. However, isometric actions require some level of force development over a given period of time, which can be assessed by the rate of force development (RFD) [15]. This is usually done by analyzing the slope of the force/time ( $\Delta$ Force/ $\Delta$ Time) curve during maximal voluntary isometric contractions. It can be calculated at fixed intervals such as $0-30,0-50,0-100$ and $0-200$ milliseconds (ms) relative to the onset of contraction [15], or by the maximum value of the first derivative of the curve [16] (Fig. 1).

Rate of force development is one of the most important capabilities for MMA athletes. Aagaard et al. [15] observed that an athlete delivers a punch in 50-250 ms. Thus, maintaining a good level of RFD is essential for sustaining knockout power during the fight. Additionally, MMA athletes are also required to develop high rates of force against opponents in order to execute 'takedown movements' [17].
This indicates that training programs for developing RFD in MMA athletes need to include the use of loaded conditions, which should often resemble fight situations. These include the use of heavier sparring opponents for practicing takedown techniques.

In biomechanical terms, there is a fundamental relation between the production of force and power, indicating that an individual cannot achieve a certain level of power without first presenting a certain level of strength [14]. Given that power is the ratio of muscle work performed at a certain time unit, the increase and maintenance of maximal strength is essential for long-term development of muscle power [14]. Several training methods favor strength development and muscle power. Among them, it is possible to highlight traditional strength training, Olympic weightlifting, plyometrics, complex training and ballistic exercises [13, 14]. Strength training methods that can be used for MMA athletes will be discussed next.

\section{TRADITIONAL STRENGTH TRAINING}

Traditional strength training represents one of the most efficient methods to promote increases in muscle strength $[13,18]$. The basis of traditional strength training is the isolation of individual muscle groups (e.g., biceps) or combination of muscle groups (e.g., chest and triceps) in order to 
maximize overload [19]. Traditional strength training involves the use of weight lifting and weight machines that are common in the gym setting. The chronic exposition to this method increases the power production ability because of the emphasis on neural and muscle adaptations, which involves both biochemical and morphological changes [13, 18].

Some possible mechanisms for neural adaptations are the increase in speed conduction and frequency of nerve stimulation, synchronization of motor units within and between muscle groups, activation of agonist muscle groups, inhibition of antagonistic muscle groups, and the attenuation of the inhibitory response of Golgi tendon organs [20]. Muscle adjustments involve alterations in intramuscular glycogen and phosphocreatine concentrations as well as in the crosssectional area of the muscle, which occurs due to the increase in size and number of myofibrils [18]. Human skeletal muscle hypertrophy is defined as a morphological adaptation characterized by an increase in the cross-sectional area of the fibers due to positive balance in the protein synthesis/degradation ratio $[21,22]$. Neural adjustments in strength-trained individuals are essentially induced by maximal strength training whereas muscle/morphological adjustments are fundamentally induced by strength endurance [19]. The first would be characterized by high intensities (weights), reduced volumes (sets, repetitions and exercises) and long intervals between sets, while the second by medium to high intensity, elevated volumes and short intervals [19].

An appropriate strength-training program for MMA should follow a periodization considering the neural and muscle adaptations abovementioned [17]. For example, a logical sequence of priorities could be the following: 1) initial strength gain, 2) hypertrophy, 3) maximum strength, 4) power, and 5) power sustainability. In this sequence, each step leads to maximization of the next. Professionals involved with MMA need to be aware of how to maximize strength-related variables in different periods of the preparation for a fight. A well-prepared athlete should demonstrate high levels of explosive power, strength, and power- and strength- endurance during most of the fight.

\section{OLYMPIC WEIGHTLIFTING}

Olympic weightlifting consists in performing two exercises: the Snatch, and the 'Clean and Jerk'. The latter exercises are extremely complex and frequently employed in strength and power training for different modalities [14, 23]. In both the Snatch and the 'Clean and Jerk' the bar is raised above the head. While in the 'Clean and Jerk' the lifting is performed in two stages, in the Snatch lifting is performed in just one stage. Both the Snatch and 'Clean and Jerk' require great capacity to accelerate the bar, causing its projection along the body and also requiring athletes to accelerate their own body weight [14]. The high ability of force production, associated with a high speed performing the movements, creates a potentially favorable environment for the development of muscle power [14, 23]. Olympic Weightlifting can increment not only power production, but also the capacity against elevated external loads [14], making it ideal for Wrestling, Rugby and American Football. The high technical complexity of the movements together with the employment of high loads are triggers for neuromuscular adaptations, allowing increases in RFD and skill transference to specific actions of MMA [14]. Thus, such exercises are practically mandatory for MMA athletes given their potential effectiveness.

\section{PLYOMETRIC TRAINING}

Plyometric training is a method emphasizing a better effectiveness in the stretch-shortening cycle [24], potentiating the contraction velocity. The method employs implements such as plinths, benches, steps and barriers, with countless variations of jumps. Some examples of plyometric exercises are jumps in general, deep jumps over plinths, barriers, steps and other obstacles providing height drops [25]. Many of these exercises can be adapted to MMA reality and help athletes to develop explosive power. Plyometric training can be effective and determinant for MMA athletes to gain power advantage over opponents. Forms of plyometric exercises for MMA training include jumping from a box/plinth and kicking, catching a medicine ball and throwing it back, etc.

\section{COMPLEX TRAINING}

This method is based on the use of strength training protocols, generally maximum strength, as potentiating exercises for subsequent activities demanding high speed for execution. This phenomenon of sharp development induced by a previous contractile activity is known as post-activation potentiation [26]. An example for MMA training would be to have athletes perform a strength exercise against a heavy resistance followed by technical actions of high speed such as punches or kicks.

\section{TRAINING ON UNSTABLE SURFACES}

Training on unstable surfaces has recently become very popular in sports [27], and the training of MMA athletes is no exception. Videos uploaded on sites such as Youtube ${ }^{\circledR}$ show MMA athletes employing instability implements in their training sessions. Currently, instability is considered a variable in strength training, which modulates acute and chronic neuromuscular responses [28]. The implements employed range from hard discs such as Wobble-boards, inflatable discs such as Dynadisc ${ }^{\circledR}$ (Exertools Inc. Meadows Petaluma, CA) and BOSU ${ }^{\circledR}$ (Hedstrom Fitness Hedstrom Drive, Ashland, OH, USA) platforms such as the T-Bow ${ }^{\circledR}$ (Swiss Therapeutic Training Products, Twinsburg, OH, USA), and Swiss balls.

Despite its common use, the inclusion of instability exercises has been associated with decrease in the ability of peak-force production, RFD and neural activity in the agonist muscle group $[28,29]$. Such effects have been observed acutely $[27,30]$ and may lead to a chronic attenuation in the 
performance of specific tests such as countermovement jumps and displacement speed [27, 29, 30]. Chulvi-Medrano and colleagues [30] examined the force production and activity of paraspinal muscles in the deadlift exercise performed under stable conditions and later with the use of two instability implements, BOSU ${ }^{\circledR}$ and $\mathrm{T}$-Bow ${ }^{\circledR}$. The results indicated that force production and muscle activity are higher in stable than unstable conditions. Similarly, McBride and colleagues [29] observed that the production of maximum isometric force and also RFD were $45.6 \%$ and $40.5 \%$ lower with the use of inflatable balls in the isometric squat when compared to the conventional version of the exercise. The integrated electromyography activity of vastus lateralis and vastus medialis was approximately $37.3 \%$ and $34.4 \%$ lower.

In terms of chronic adaptations, Cressey and colleagues [27] reported that 10 weeks of training with additional exercises on unstable discs resulted in attenuation of increments in power and displacement speed in football athletes when compared to a group training on stable surfaces only. The authors concluded that complementing the conventional training with instability implements might result in attenuations of increments in strength and muscle power. These results suggest that instability equipment should not be employed in MMA training. Using such devices can lead to attenuation in the increment of strength and muscle power. It can also result in detrimental neural adaptations such as greater activation of agonist and inhibition of antagonists muscle groups, leading to considerable delay and loss in the physical training process of the athletes.

\section{ACUTE RAPID WEIGHT LOSS IN MMA ATHLETES}

All athletes in MMA are required to attain a specific body weight (weight class) before competing in a regulated bout. The purpose of weight classes is to match athletes that are of similar sizes and strength levels, attempting to equalize their physical status and minimize the risk of injuries [31]. Meanwhile, many athletes adopt the strategy of drastically reducing their body weight prior to the official weighin so that they qualify for the intended weight class, and hypothetically gain some physical advantage over the opponent.

Studies with wrestling [32, 33], judo [34] and more recently with MMA athletes [31] report that the competitors reduce their body weight in a relatively short time prior to the official event. The acute rapid weight loss is often made by a combination of potentially harmful strategies like severe food restriction and fluid intake, saunas, training in the heat, use of diuretics and laxatives, and the induction of vomiting $[34,35]$. However, such strategies have negative physiological consequences leading to an impairment of the athletic performance and health [36]. Adverse effects include impaired glycogen use, central nervous system dysfunction, increases in core temperature, cardiovascular strain and dehydration-related health issues [37]. In 1997, three collegiate wrestlers allegedly died from heat-related stroke caused by dehydration levels ranging from 6.7 to $10 \%$ body weight [38].
Recently, Jetton et al. [31] quantified the extent of dehydration, acute weight gain, and rehydration in MMA athletes before competition. Urinary measures of hydration status and body mass were determined 24 hours before and then again approximately 2 hours before competition in 40 MMA athletes. The results showed that the MMA athletes gained a mean of $3.4 \mathrm{~kg}$ or $4.4 \%$ of their body weight approximately 22 hours before competition. Thirty-nine percent of the athletes presented with a urine specific gravity of 1.02 immediately before competition, indicating serious dehydration. Urinary measures of hydration status indicate that a significant proportion of MMA athletes are not successfully rehydrating before competition and subsequently are competing in a dehydrated condition. It has been reported that dehydration inhibits performance and may induce health risks that can potentially lead to death [38]. We recommend that MMA governing bodies, both at national and international levels, take a proactive approach in education and implementation of weight management regulations that could prevent rapid weight loss in MMA events.

\section{FREE RADICAL METABOLISM IN FIGHTERS}

In a recent study, Greek researchers simulated a regular competition day of wrestling and found interesting results [39]. The competition-simulating test was able to reproduce fatigue indices quite compatible to those reported in actual competitions, demonstrating a high energy demand in Greek elite fighters (average heart rate $>85 \%$ and lactate concentrations $>17 \mathrm{mM}$ ). Markers of inflammation (release of IL- 6 and C-reactive protein) and oxidative stress (levels of lipid and protein oxidation, GSH depletion, and activation of the antioxidant enzymes catalase and glutathione peroxidase) showed significant redox imbalance after the first clash between wrestlers, which gradually increased throughout the 4th qualifying fight.

Douris et al. [40] evaluated glutathione-dependent antioxidant responses in middle-aged adults training Soo Bahk Do, a traditional Korean martial art. The results showed that Soo Bahk Do practitioners have higher GSH background levels than sedentary individuals of similar age, and a better response to oxidative challenges imposed by a standardized physical test. The authors suggest that frequent practice of Soo Bahk Do positively improves the antioxidant defensive system of individuals making them less susceptible to infections and to other ROS/RNS-mediated diseases. Similar antioxidant variations were also observed in the plasma of Serbian karatekas at the end of an extended training program. Interestingly, motivational aspects and mental conditions of fighting athletes were also linked to molecular events and to the metabolism of ROS/RNS [41].

Although the molecular basis of ROS/RNS production during exercise is already well established, conflicting results have been observed in regard to antioxidant supplementation as a coadjutant strategy to improve athletic performance [42]. However, most of the evidence indicates the efficiency of antioxidant supplementation in the redox balance during and after physical activity [42]. Therefore, MMA 
athletes may benefit from antioxidant supplementation during training and competition periods.

\section{CONCLUDING REMARKS}

MMA is an exciting and complex combat sport. Despite the well-documented training methods for other intermittent modalities, little is known and reported about more specific and efficient means and methods for the improvement of physical performance in MMA. The present study provide a review on important aspects related to MMA training and physiology that need to be considered for successful preparation of athletes. Considering the constant growing of the modality around the world, we recommend that future studies examine physical demands and other determinant aspects for high performance in MMA.

\section{CONFLICT OF INTEREST}

The authors confirm that this article content has no conflict of interest.

\section{ACKNOWLEDGEMENTS}

Declared none

\section{REFERENCES}

[1] Woodward TW. A review of the effects of martial arts practice on health. WMJ 2009; 108(1): 40-3.

[2] Kochhar T, Back DL, Mann B, Skinner J. Risk of cervical injuries in mixed martial arts. $\mathrm{Br} \mathrm{J}$ Sports Med 2005; 39: 444-7. doi:10.1136/bjsm.2004.011270.

[3] Lenetsky S, Harris N. The mixed martial arts athlete: a physiological profile. Strength Cond J 2012; 34: 32-47. doi:10.1519/SSC. 0b013e3182389f00.

[4] Bounty PL, Campbell BI, Galvan E, Cooke M, Antonio J. Strength and conditioning considerations for mixed martial arts. Strength Cond J 2011; 33: 56-67. doi:10.1519/SSC.0b013e3182044304.

[5] Association of Boxing Commissions. Unified Rules for MMA. New Orleans, LA 2009.

[6] Buse GJ. No holds barred sport fighting: a 10 year review of mixed martial arts competition. Br J Sports Med 2006; 40: 169-72. doi:10.1136/bjsm.2005.021295.

[7] Amtmann JA, Amtmann KA, Spath WK. Lactate and rate of perceived exertion responses of athletes training for and competing in a mixed martial arts event. J Strength Cond Res 2008; 22(2): 645-7. doi:10.1519/JSC.0b013e318166018e.

[8] Hawley JA. Adaptations of skeletal muscle to prolonged, intense endurance training. Clin Exp Pharmacol Physiol 2002; 29: 218-22.

[9] Lourenço TF, Martins LEB, Tessutti LS, Brenzikofer R, Macedo DV. Reproducibility of an incremental treadmill VO(2)max test with gas exchange analysis for runners. J Strength Cond Res 2011; 25: 1994-9. doi:10.1519/JSC.0b-013e3181e501d6.

[10] Billat LV. Interval training for performance: a scientific and empirical practice. Special recommendations for middle- and longdistance running. Part I: aerobic interval training. Sports Med 2001; 31(1): 13-31.

[11] Toubekis AG, Douda HT, Tokmakidis SP. Influence of different rest intervals during active or passive recovery on repeated sprint swimming performance. Eur J Appl Physiol 2005; 93: 694-700. doi:10.1007/s00421-004-1244-9.

[12] Gladden LB. Lactate metabolism: a new paradigm for the third millennium. J Physiol 2004; 558: 5-30. doi:10.1113/jphysiol.2003 .058701 .

[13] Cormie P, McGuigan MR, Newton RU. Developing maximal neuromuscular power: Part 1--biological basis of maximal power production. Sports Med 2011; 41:17-38. doi:10.2165/11537690000000000-00000.
[14] Cormie P, McGuigan MR, Newton RU. Developing maximal neuromuscular power: part 2 - training considerations for improving maximal power production. Sports Med 2011; 41: 125-46 doi:10.2165/11538500-000000000-00000.

[15] Aagaard P, Simonsen EB, Andersen JL, Magnusson P, DyhrePoulsen P. Increased rate of force development and neural drive of human skeletal muscle following resistance training. J Appl Physiol (1985) 2002; 93: 1318-26. doi:10.1152/japplphysiol. 00283.2002 .

[16] Mirkov DM, Nedeljkovic A, Milanovic S, Jaric S. Muscle strength testing: evaluation of tests of explosive force production. Eur J Appl Physiol 2004; 91: 147-54. doi:10.1007/s00421-003-0946-8.

[17] James LP, Kelly VG, Beckman EM. Periodization for mixed martial arts. Strength Cond J 2013; 35: 34-45. doi:10.1519/SSC.0000000000000017 .

[18] Folland JP, Williams AG. The adaptations to strength training : morphological and neurological contributions to increased strength. Sports Med 2007; 37: 145-68.

[19] Kraemer WJ, Häkkinen K. Handbook of sports medicine and science, strength training for sport. John Wiley \& Sons 2008.

[20] Häkkinen K. Neuromuscular and hormonal adaptations during strength and power training. A review. J Sports Med Phys Fitness 1989; 29(1): 9-26.

[21] Bassel-Duby R, Olson EN. Signaling pathways in skeletal muscle remodeling. Annu Rev Biochem 2006; 75: 19-37. doi:10.1146/annurev.biochem.75.103004.142622.

[22] Chargé SBP, Rudnicki MA. Cellular and molecular regulation of muscle regeneration. Physiol Rev 2004; 84: 209-38. doi:10.1152/physrev.00019.2003.

[23] Schilling BK, Stone MH, O'Bryant HS, Fry AC, Coglianese RH, Pierce KC. Snatch technique of collegiate national level weightlifters. J Strength Cond Res 2002; 16: 551-5.

[24] Markovic G, Mikulic P. Neuro-musculoskeletal and performance adaptations to lower-extremity plyometric training. Sports Med 2010; 40: 859-95. doi:10.2165/11318370-000000000-00000.

[25] Byrne PJ, Moran K, Rankin P, Kinsella S. A comparison of methods used to identify "optimal" drop height for early phase adaptations in depth jump training. J Strength Cond Res 2010; 24: 20505. doi:10.1519/JSC. 0b013e3181d8eb03.

[26] Tillin NA, Bishop D. Factors modulating post-activation potentiation and its effect on performance of subsequent explosive activities. Sports Med 2009; 39: 147-66.

[27] Cressey EM, West CA, Tiberio DP, Kraemer WJ, Maresh CM. The effects of ten weeks of lower-body unstable surface training on markers of athletic performance. J Strength Cond Res 2007; 21(2): 561-7. doi:10.1519/R-19845.1.

[28] Anderson K, Behm DG. The impact of instability resistance training on balance and stability. Sports Med 2005; 35:43-53.

[29] McBride JM, Cormie P, Deane R. Isometric squat force output and muscle activity in stable and unstable conditions. J Strength Cond Res 2006; 20(4): 915-8. doi:10.1519/R-19305.1.

[30] Chulvi-Medrano I, García-Massó X, Colado JC, Pablos C, de Moraes JA, Fuster MA. Deadlift muscle force and activation under stable and unstable conditions. J Strength Cond Res 2010; 24(10): 2723-30. doi:10.1519/JSC.0b013e3181 f0a8b9.

[31] Jetton AM, Lawrence MM, Meucci M, et al. Dehydration and acute weight gain in mixed martial arts fighters before competition. J Strength Cond Res Natl Strength Cond Assoc 2013; 27(5): 1322-6. doi:10.1519/JSC.0b013e 31828a1e91.

[32] Alderman BL, Landers DM, Carlson J, Scott JR. Factors related to rapid weight loss practices among international-style wrestlers. Med Sci Sports Exerc 2004; 36(2): 249-52. doi:10.1249/01. MSS.0000113668.03443.66.

[33] Oppliger RA, Utter AC, Scott JR, Dick RW, Klossner D. NCAA rule change improves weight loss among national championship wrestlers. Med Sci Sports Exerc 2006; 38(5): 963-70. doi:10.1249/01.mss.0000218143.69719.b4.

[34] Artioli GG, Gualano B, Franchini E, et al. Prevalence, magnitude, and methods of rapid weight loss among judo competitors. Med Sci Sports Exerc 2010; 42: 436-42. doi:10.1249/MSS.0b013e3181 ba8055.

[35] Oppliger RA, Steen SAN, Scott JR. Weight loss practices of college wrestlers. Int J Sport Nutr Exerc Metab 2003; 13(1): 29-46.

[36] Artioli GG, Franchini E, Nicastro H, Sterkowicz S, Solis MY, Lancha $\mathrm{AH}$. The need of a weight management control program in 
judo: a proposal based on the successful case of wrestling. J Int Soc Sports Nutr 2010; 7: 15. doi:10.1186/1550-2783-7-15.

[37] Cheuvront SN, Carter R, Sawka MN. Fluid balance and endurance exercise performance. Curr Sports Med Rep 2003; 2: 202-8.

[38] Centers for Disease Control and Prevention. Hyperthermia and dehydration-related deaths associated with intentional rapid weight loss in three collegiate wrestlers--North Carolina, Wisconsin, and Michigan, November-December 1997. JAMA 1998; 279: 824-5.

[39] Barbas I, Fatouros IG, Douroudos II, et al. Physiological and performance adaptations of elite Greco-Roman wrestlers during a oneday tournament. Eur J Appl Physiol 2011; 111: 1421-36. doi:10.1007/s00421-010-1761-7.
[40] Douris PC, Elokda AS, Handrakis JP, et al. Martial art training enhances the glutathione antioxidant system in middle-aged adults. J Strength Cond Res 2009; 23: 1518-23. doi:10.1519/JSC.0b013e $3181 \mathrm{~b} 339 \mathrm{ac}$.

[41] Pesić S, Jakovljević V, Cubrilo D, et al. [Oxidative status evaluation in elite karate athletes during training process. Vojnosanit Pregl Mil-Med Pharm Rev 2009; 66: 551-5.

[42] Bloomer RJ, Falvo MJ, Schilling BK, Smith WA. Prior exercise and antioxidant supplementation: effect on oxidative stress and muscle injury. J Int Soc Sports Nutr 2007; 4: 9. doi:10.1186/15502783-4-9.

(C) Souza-Junior et al.; Licensee Bentham Open.

This is an open access article licensed under the terms of the Creative Commons Attribution Non-Commercial License (http://creativecommons.org/licenses/ by-nc/3.0/) which permits unrestricted, non-commercial use, distribution and reproduction in any medium, provided the work is properly cited. 